\title{
PEDAGOGY
}

\section{PROBLEMS RELATED TO PEDAGOGICAL SUPPORT SYSTEM OF CHILDREN WITH HEARING IMPAIRMENT OR DISORDERS IN REPUBLIC OF ARMENIA}

\author{
Babayan L. A., Lecturer, candidate of pedagogical sciences, associate professor \\ Manukyan N. N., master,
}

Armenian State Pedagogical University named after Khachatur Abovian, Yerevan, Armenia

DOI: https://doi.org/10.31435/rsglobal_ws/31032020/6983

\section{ARTICLE INFO}

Received: 05 January 2020

Accepted: 11 March 2020

Published: 31 March 2020

\section{KEYWORDS}

hearing disorders,

story perception,

distinctive features

\begin{abstract}
In this article distinctive features related to the characteristic of children with hearing disorders due to story perception, teachers' awareness level of research results related to mentioned problems, and some cultivated and justified approaches are presented. All researches are implemented in Republic of Armenian Tigranyan № 14 special school.
\end{abstract}

Citation: Babayan L. A., Manukyan N. N. (2020) Problems Related to Pedagogical Support System of Children with Hearing Impairment or Disorders in Republic of Armenia. World Science. 3(55), Vol.3. doi: 10.31435/rsglobal_ws/31032020/6983

Copyright: (C) 2020 Babayan L. A., Manukyan N. N. This is an open-access article distributed under the terms of the Creative Commons Attribution License (CC BY). The use, distribution or reproduction in other forums is permitted, provided the original author(s) or licensor are credited and that the original publication in this journal is cited, in accordance with accepted academic practice. No use, distribution or reproduction is permitted which does not comply with these terms.

It is obvious that hearing sensorineural disorders are the most common problems for both children and parents. It has negative impact on children's cognition, communication and development forms of other activities. A child with hearing impairment has the same requirements as a normal child, but he is unable to communicate with his surrounding world.

Children with hearing impairment not only face with hearing disorders but also would accompany with several disorders. This was obvious even several years ago when there were not any technical objective measurements in order to discover hearing loss in early ages. The doctors and educators were compelled to measure the hearing by speaking or sound reflectors which were extremely subjective and were not able to give exact and accurate information about children's hearing impairment's nature and level.

For this reason, the final diagnosis was often made after the age of 3 and omitted the sensory area of speech development. (Impaired speech, mental and emotional development disorders) lead to disability and only through early medical and psychological support provided for the child, he can be included in society and become a full member of it. That is why early detection of congenital hearing disorders is a pressing and important issue in the world and also in Armenia nowadays.

Unfortunately, with neurosensor hearing loss or disorders and deafness, medicine is still unable to restore hearing. Therefore, it is very difficult for parents to accept their children's problem. They do not imagine and do not want to believe that their children will never hear and because of that they will not speak.

However, due to the use of modern techniques, hearing loss may be compensated by hearing aids or cochlear implant. 
Only early learning can create conditions for a child's normal mental and intellectual development. Early detection and diagnosis of hearing impairment is an important prerequisite for timely pedagogical support in the family. From the early months of the life of children with hearing impairments, pediatric intervention allows to get the best results which will lead to the normal development of verbal and mental functions.

As the pedagogical experience shows, at the age of three, the level of speech and overall development of these children is closer to their peers having normal hearing. All this allows the child to fully integrate into the pre-school environment.

In fact, due to the use of modern techniques, early detection of hearing impairments, acoustic compensation, and the implementation of surdo-pedagogical activities are considered important and relevant, since children with hearing loss who are not diagnosed at an early age have a growing number of years of communication, social and educational disabilities, which subsequently leads to difficulties in choosing a job and in general for being involved in society. This is the reason for the modernity of our work.

Purpose of the study: Identify the problem of the support system for children with hearing impairments in the Republic of Armenia and justify the ways of their solution.

\section{Problem of the study:}

1. Investigate the need for early detection of hearing loss and the application of technical means in the process.

2. Identify the need to apply hearing aids to increase the effectiveness of surdo-pedagogical development.

3. Evaluate the development of early identified and supported hearing-impaired children and compare it with the development of normal hearing children.

Thus, medical measures of Diagnosis and Compensation will be ineffective if they are not immediately followed by socio-psychological and pedagogical rehabilitative works.

In Armenia, these activities are carried out in the unique preschool rehabilitation center adjacent to the Arabkir Medical Complex and its regional branches in Gyumri, Vanadzor, Gavar, Kapan, Artashat, Yeghegnadzor.

Parents of early childhood hearing impaired children included in this service are included in the counseling groups, their parents receiving necessary sourdough dialysis assistance and psychological support.

Pedagogical methods (observation, inquiry, conversation, case study) allowed to evaluate the use of technical means in early intervention of hearing impairments, to determine the specifics of the organization and conduct of this work, the awareness and attitude of specialists and senior students toward the major problem in this field of research.

During the study, we performed a comparative analysis, which revealed the level of speech, hearing perception, and overall development of children with early-diagnosed and early sudo-pediatric intervention and those left out of the early intervention program.

Thus, through the above research conditions, we have been able to identify the current state of the problem under study, the peculiarities of the use of technical tools in the work with the children under study, and their impact on the development of children, as well as to determine the research direction of their work and the main ways of solving existing problems.

Thus, the results of our studies and our research on the methodological literature, our use of the systematic tools, approaches and methods available in the scientific and methodological literature, as well as our complementary evidence of effectiveness and positive impact.

\section{REFERENCES}

1. Davtyan S.R. Evaluation and development of spatial orientation abilities of preschool children with visual impairment in family. Educational-methodical guide. "Nahapet" publishing house, Yerevan city, (2018), page 47

2. Davtyan S.R. Evaluation and development of spatial orientation abilities of preschool children with visual impairment in family. Problems and opportunities of educational development. Second All-Russian Scientific and practical Conference (with international participation), Orekhovo-Zuevo city, (2018), page 21-23

3. Deniskina V.Z. Characteristics of visual perception of blind people having residual vision. Deniskina V.Z. - Defectology, (2018) Number 5, page 56-65

4. Sapp, W., \& Hatlen, P. (2010) The expanded core curriculum: Where we have been, where we are going, and how we can get there. Journal of Visual Impairment \& Blindness, 104, 338-348 